\title{
Trichotillomania: a good response to treatment with $\mathrm{N}$-acetylcysteine*
}

\author{
Livia Ariane Lopes Barroso ${ }^{1}$ \\ Maria Natalia Inacio de Fraia e Souza ${ }^{1}$
}

\author{
Flavia Sternberg ${ }^{1}$ \\ Gisele Jacobino de Barros Nunes ${ }^{1}$
}

DOI: http:/ /dx.doi.org/10.1590/abd1806-4841.20175435

\begin{abstract}
Trichotillomania is considered a behavioral disorder and is characterized by the recurring habit of pulling one's hair, resulting in secondary alopecia. It affects $1 \%$ of the adult population, and 2 to $4.4 \%$ of psychiatric patients meet the diagnostic criteria. It can occur at any age and is more prevalent in adolescents and females. Its occurrence in childhood is not uncommon and tends to have a more favorable clinical course. The scalp, eyebrows and eyelashes are the most commonly affected sites. Glutamate modulating agents, such as N-acetylcysteine, have been shown to be a promising treatment. N-acetylcysteine acts by reducing oxidative stress and normalizing glutaminergic transmission. In this paper, we report a case of trichotillomania with an excellent response to $\mathrm{N}$-acetylcysteine.
\end{abstract}

Keywords: Acetylcysteine; Alopecia; Glutamates; Trichotillomania

\section{INTRODUCTION}

Trichotillomania is considered a behavioral disorder and is characterized by the recurring habit of pulling one's hair, resulting in secondary alopecia. The term trichotillomania was first used in 1889 by Hallopeau and is derived from the Greek thrix (hair), tillein (to pull) and mania (madness). It affects $1 \%$ of the adult population, and $2 \%$ to $4.4 \%$ of psychiatric patients meet the diagnostic criteria. ${ }^{1-3}$ It can occur at any age but is more prevalent in adolescents and females $(88 \%$ to $94 \%$ ). Its occurrence in childhood is not uncommon and tends to have a more favorable clinical course. ${ }^{2,4}$ The scalp, eyebrows and eyelashes are the most commonly affected sites, but any body area may be affected. Approximately $30 \%$ of patients have a habit of swallowing the hair, leading to the development of trichobezoar, resulting in serious gastrointestinal complications. ${ }^{1}$ Several treatments have been proposed, including psychotherapy and the use of selective serotonin reuptake inhibitors (SSRIs). Due to the side effects of SSRIs, which are associated with high doses and their incomplete symptom control, it is essential to seek other treatment options, such as glutamate modulating agents. $\mathrm{N}$-acetylcysteine is a glutamate modulating agent that appears to offer a promising treatment option. It acts by reducing oxidative stress and normalizing glutaminergic transmission. ${ }^{6}$ In this study, we report a case of trichotillomania with an excellent response to $\mathrm{N}$-acetylcysteine. ${ }^{5,6}$

\section{CASE REPORT}

The patient was an 11-year-old male student, born and living in the state of São Paulo (SP). He reported the occurrence of thinning hair on the scalp over the previous six months. The mother said that the child had a habit of pulling out his hair. The patient was in irregular counseling and had developed a relationship problem with his father. He had a personal history of asthma and atopic dermatitis. A dermatological examination revealed an extensive area of alopecia in the frontal region. Gentle traction was negative

Received on 28.11.2015

Approved by the Advisory Board and accepted for publication on 18.02.2016

* The study was conducted in the Trichology Outpatient Clinic, Department of Cosmetology, Unifesp - São Paulo (SP), Brazil.

Financial support: none.

Conflict of interest: none.

1 Trichology Outpatient Clinic, Department of Cosmetology, Universidade Federal de São Paulo (Unifesp) - São Paulo (SP), Brazil.

(C)2017 by Anais Brasileiros de Dermatologia 
(Figures 1 and 2). Dermoscopy revealed the presence of broken hairs of different sizes, multiple black spots and a V-sign (Figure 3). Treatment with $\mathrm{N}$-acetylcysteine was therefore initiated $(1200 \mathrm{mg} /$ day for three months). The patient's outlook improved dramatically, but complete remission was not achieved. We chose to increase the dosage to $1800 \mathrm{mg}$ /day, which resulted in almost complete regrowth (Figure 4).

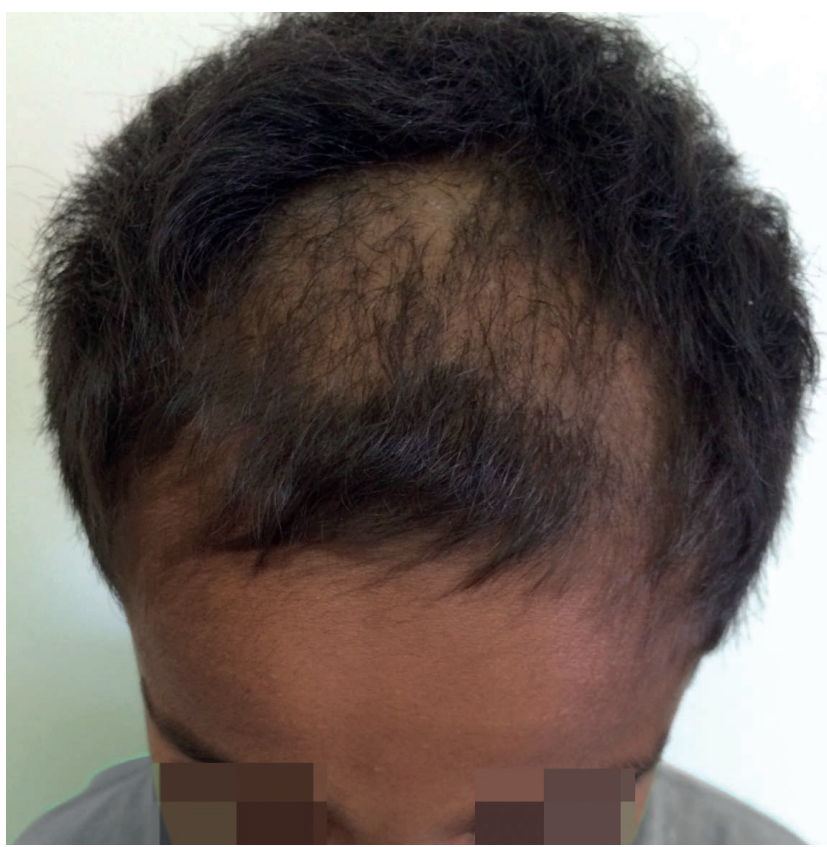

FIGURE 1: Significant thinning of the hair in the frontal region

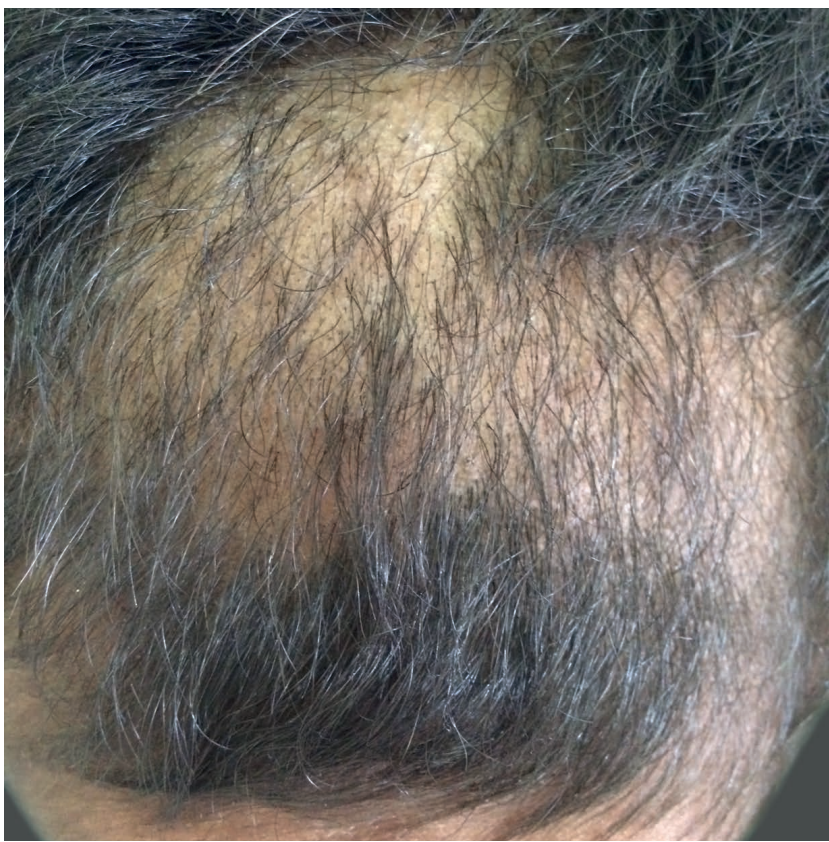

FIGURE 2: Presence of thinning hair with hairs of different lengths

\section{DISCUSSION}

Trichotillomania, which was previously included in the obsessive-compulsive disorder (OCD) spectrum, was reclassified as an OCD-related disorder (OCDRD) in the fifth edition of the Diagnostic and Statistical Manual of Mental Disorders (DSM-5). Clinical similarities between these types of disorders exist, but the epidemiologi-

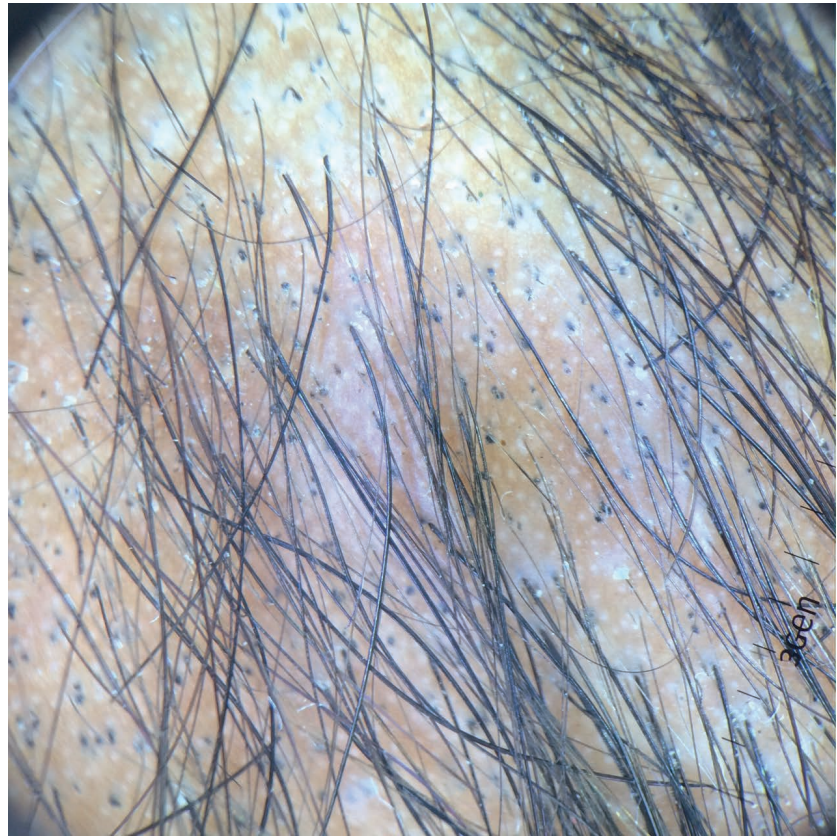

FIGURE 3: Dermoscopy showing broken hairs of different lengths, black spots and a V-sign

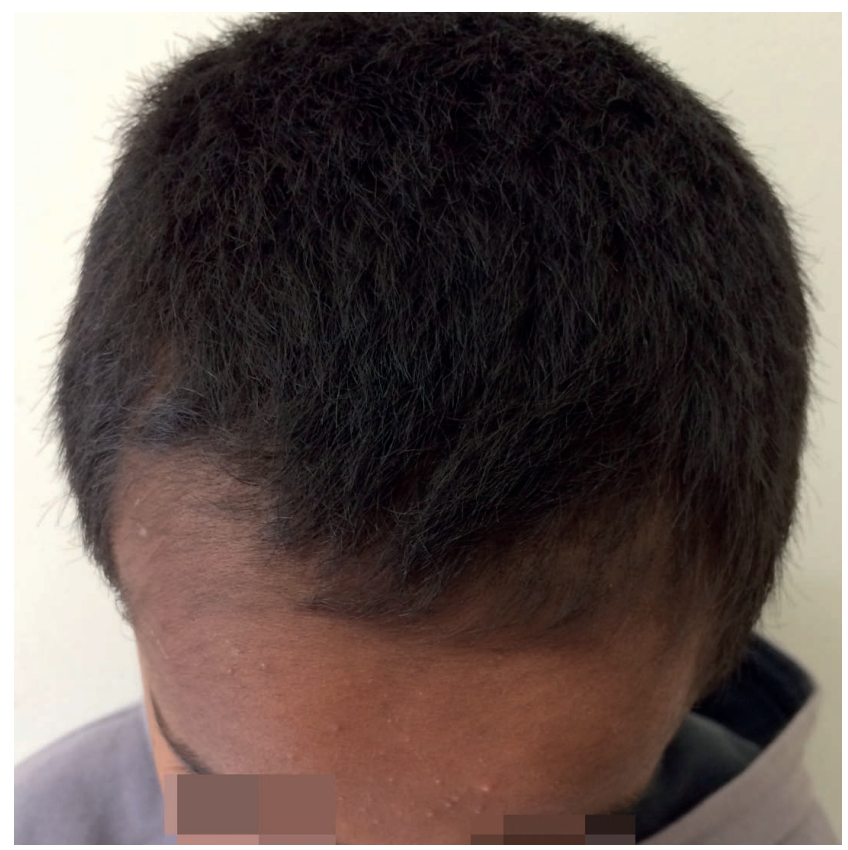

FIGURE 4: Improvement after six months of treatment 
cal differences and different clinical response to drugs used suggest pathophysiological differences. Trichotillomania has a negative impact on the patient's quality of life, interfering with social, personal and occupational life. ${ }^{4,6}$ The diagnosis of trichotillomania remains challenging and is established on a clinical, dermoscopic and histopathological basis. Dermoscopy is a noninvasive method that appears to be a very useful tool that increases diagnostic accuracy and reduces the need for biopsy. ${ }^{1-3}$ Classical dermoscopic signs include decreased capillary density, broken hairs, black spots, trichoptilosis, short vellus, yellow spots and exclamation mark hairs. New, more specific trichoscopic findings have been described, such as a V-sign, tulip hairs, flame hair, hook hairs, hair powder and follicular microhemorrhage. The main differential diagnosis is alopecia areata. Some dermoscopic signs are common to both entities. The black spots observed in trichotillomania exhibit variability in diameter and shape, distinguishing them from alopecia areata, in which these spots are uniform. ${ }^{1-3}$ Histopathology reveals a non-scarring alopecia pattern with a distorted and collapsed inner root sheath, empty follicles, pigmented casts and trichomalacia. ${ }^{1}$ Various treatments have been proposed, including psychotherapy and the use of SSRIs. Due to the side effects of SSRIs, which are associated with high doses and their incomplete symptom control, it is essential to seek other treatment options, such as glutamate modulating agents., ${ }^{4,6}$ Evidence suggests the presence of abnormalities in glutamate metabolism in patients with OCDs. High levels of glutamate are associated with cytotoxicity and increased oxidative stress, which is correlated with symptom severity. Although the role of glutamate in OCDRD neurobiology has not yet been demonstrated in brain imaging studies, the ability of glutamate modulating agents to regulate impulse control is remarkable, which makes these drugs of great interest for the treatment of trichotillomania. N-acetylcysteine is a glutamate modulating agent that appears to offer a promising treatment option. It has neurochemical, antioxidant, mucolytic, anti-inflammatory and hepatoprotective actions and acts by reducing oxidative stress and normalizing glutaminergic transmission. It is widely used and does not require a prescription. After oral administration, N-acetylcysteine undergoes deacetylation in the liver, producing cysteine, which is used as a substrate for glutathione production, which is a potent endogenous antioxidant. Cysteine is thought to cross the bloodbrain barrier via sodium-dependent transporters and is then converted to cystine. High levels of cystine stimulate glutamate-cystine exchange via the glutamate-cystine transporter, which increases non-synaptic glutamate levels. This process activates glutamate receptors (mGluR2/3) in the presynaptic neurons responsible for the inhibition of synaptic glutamate release and restores extracellular levels of this substance. In the intracellular environment, cystine is then converted to cysteine, which is used to produce glutathione. The regulation of this transporter system has been shown to improve impulse control and play a key role in OCDRDs such as trichotillomania. ${ }^{4,6}$

\section{REFERENCES}

1. Ankad BS, Naidu MV, Beergouder SL, Sujana L. Trichoscopy in Trichotillomania: a useful diagnostic tool. Int J Trichology. 2014;6:160-3.

2. Yorulmaz A, Artuz F, Erden 0. A case of Trichotillomania with recently defined trichoscopic findings. Int J Trichology. 2014;6:77-9.

3. Park J, Kim JI, Kim HU, Yun SK, Kim SJ. Trichoscopic Findings of Hair Loss in Koreans. Ann Dermatol. 2015;27:539-50.

4. Cortés AG, Mardones FV, Zemelman VD. Caracterización de las causas de alopecia infantil. Rev Chil Pediatr. 2015;86:264-9.

5. Grados MA, Atkins EB, Kovacikova Gl, McVicar E. A selective review of glutamate pharmacological therapy in obsessive-compulisive and related disorders. Psychol Res Behav Manag. 2015;8:115-31.

6. Oliver G, Dean O, Camfield D, Blair-West S, Ng C, Berk M, et al. N-acetyl cysteine in the treatment of Obsessive Compulsive and Related Disorders: a systematic review. Clin Psychopharmacol Neurosci. 2015;13:12-24.

\author{
MAILING ADDRESS: \\ Livia Ariane Lopes Barroso \\ Rua Estado de Israel, 192 \\ Vila Clementino \\ 04022-000 São Paulo, SP, Brazil \\ E-mail:livia_lopes2002@yahoo.com.br
}

How to cite this article: Barroso LAL, Sternberg F, Souza MNIF, Nunes GJB. Trichotillomania: a good response to treatment with N-acetylcysteine. An Bras Dermatol. 2017;92(4):537-9 